\title{
INCIDÊNCIA DE INTOXICAÇÕES POR PRAGUICIDAS NO PARANÁ
}

\author{
INCIDENCE OF PESTICIDE POISONING IN PARANA STATE
}

GABRIEL, M. M ${ }^{1 *}$,; LOPES, M. ${ }^{1,2}$; SILVA, E.T. ${ }^{3}$, BARETA, G.M.S. ${ }^{1}$

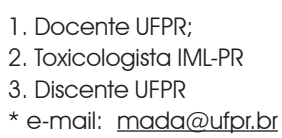

Recebido em: 02/2004 Aprovado em: 05/2004

RESUMO

A importância dos praguicidas como agente causal de intoxicações e óbitos é evidenciada pelo número de ocorrências registradas. No Brasil ocupam a terceira posição dentre os agentes responsáveis pelas intoxicações agudas. Foi realizado levantamento no Centro de Informações Toxicológicas do Paraná (CIT) e no Instituto Médico Legal do Paraná (IML-PR) das intoxicações por praguicidas no período de 10/2000 a 08/2003. Neste período o CIT recebeu 1904 notificações de intoxicações e 224 intoxicações com óbito, enquanto que o IML registrou 120 óbitos provocados por praguicidas. Nos registros do IML, foram identificadas várias classes de praguicidas, havendo incidência de carbamatos na ordem de $39,2 \%$ e entre eles o aldicarb, conhecido popularmente como chumbinho. Os resultados confirmam a situação crítica quanto ao uso inadequado de praguicidas no Estado do Paraná, indicando a necessidade de orientação ao consumidor e adequada vigilância sanitária quanto ao uso e comercialização dos mesmos.

Palavras-chave - intoxicação por praguicidas, carbamatos, chumbinho, Aldicarb

\section{ABSTRACT}

The importance of the pesticide as causal agent of intoxication and deaths is clearly shown by the number of registered cases. In Brazyl the pesticide are the third more important group of substances responsible for acute intoxication. A search for pesticide poisoning was made in the Parana State's Poisoning Information Center and in the Institute for Legal Medicine from October, 2000 through August, 2003. In this period the Poisoning Information Center received 1,904 poisoning notifications and 224 poisoning cases with death. In the same period, the Institute for Legal Medicine recorded 120 deaths caused by pesticides. In the Institute for Legal Medicine's file records it was found that the carbamates pesticides contributed with $39,2 \%$ of those fatal cases, being the Aldicarb (popularly known in Brazil as "bullets") the main toxicological agent. The situation in Parana State is a critical one if it is taken into consideration that the use of pesticides by the population at large is made in a indiscriminate way and without the appropriate vigilance by the sanitary authorities.

Keywords: pesticide intoxication, carbamates, bullet, aldicarb

\section{INTRODUÇÃO}

Inúmeros praguicidas são comercializados no Brasil, num total de 1200 marcas. No Estado do Paraná, apenas 744 do total destas marcas são liberadas para uso, em conseqüência de uma legislação específica do Estado (PARANÁ, 2004). Permanentemente, a Secretaria de Estado da Agricultura e de Abastecimento (SEAB) atualiza a lista de praguicidas aprovados; esta evolução é observada pelo acréscimo, nos últimos 2 anos, de 50 novos produtos (GABRIEL et al, 2002).

Vale ressaltar que os praguicidas são substâncias químicas, cujo uso é amplamente difundido no mundo e, em razão de serem responsáveis por inúmeros casos de intoxicação, merecem atenção quanto à racionalidade no seu emprego. No Brasil já aparecem na terceira posição dentre os agentes causais das intoxicações agudas, sendo os inseticidas (organofosforados, piretróides, carbamatos e organoclorados) os responsáveis pelo maior número de ocorrências (ALONZO; CORRÊA, 2003).

Contudo o meio científico nacional apresenta, hoje, preocupação com a incidência de intoxicações causadas pelo carbamato aldicarb conhecido popularmente por 
chumbinho (MORAES, 1999; CANASVIEIRAS, et al, 200?), que está sendo usado, pela população, como iscas para ratos. Este carbamato tem seu uso aprovado somente como inseticida, não sendo permitido seu uso como raticida, por apresentar alta toxicidade e necessitar de cuidados especiais para sua manipulação (LARINE, 1996).

\section{OBJETIVO}

Determinar o número de intoxicações registradas no Estado do Paraná a partir de registros do Instituto Médico Legal do Paraná (IML-PR) e do Centro de Informações Toxicológicas da Secretaria Estadual de Saúde (CIT) no período de 10/2000 a 08/2003, evidenciando o uso do carbamato aldicarb.

\section{MATERIAL E MÉTODO}

Foi realizada análise retrospectiva nos registros de intoxicações por praguicidas no CITPR e no Laboratório de Toxicologia do IML-PR, no período de outubro de 2000 a setembro de 2003. Os dados foram organizados em tabelas e gráficos de modo a identificar as ocorrências das intoxicações, óbitos e as principais classes de praguicidas causadores das intoxicações.

\section{RESULTADOS E DISCUSSÃO}

Os dados obtidos no levantamento dos registros de intoxicação por praguicidas (tabela1) indicam número relevante de casos de intoxicações no Estado do Paraná, sem contudo identificar a característica da intoxicação (ocupacional, acidental ou voluntária) ou a faixa etária dos indivíduos comprometidos.

TABELA 1 - Ocorrência das intoxicações

\begin{tabular}{cccc}
\hline Ano & $\begin{array}{c}\text { Número de } \\
\text { notificações }\end{array}$ & $\begin{array}{c}\text { Intoxicações } \\
\text { com morte }\end{array}$ & $\begin{array}{c}\text { Análises } \\
\text { pós-morte IML }\end{array}$ \\
\hline $10 / 2000$ & 158 & 21 & 9 \\
2001 & 720 & 96 & 45 \\
2002 & 580 & 66 & 42 \\
$8 / 2003$ & 446 & 38 & 24 \\
Total & 1904 & 224 & 120 \\
\hline
\end{tabular}

FONTE: IML-PR/ CIT

O CIT registrou 1904 casos de intoxicações com 224 mortes, enquanto que o IML-PR, 120 óbitos por intoxicações por praguicidas.

Tais dados não podem ser agrupados, devido a falta de informações se os óbitos registrados pelo IML-PR fazem parte dos registros do CIT, pois o primeiro é um órgão forense e o segundo, um órgão informativo.

Nos dados obtidos no IML-PR estão identificadas as classes de praguicidas responsáveis pelas intoxicações, cuja incidência está registrada no gráfico 1. 


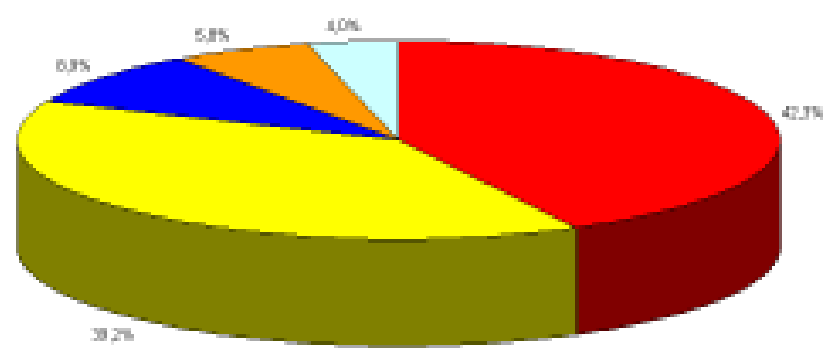

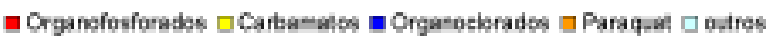

GRÁFICO 1 - Incidência (\%) das intoxicações por praguicidas no Paraná no período de 10/2000 a 08/2003.

FONTE: IML-PR, 2003

O maior número de intoxicações ocorreu pelos inseticidas organofosforados (42,3\%), seguido pelos inseticidas carbamatos $(39,2 \%)$ e pelas demais classes, em valores inferiores a $20 \%$.

Convém ressaltar que entre os inseticidas carbamatos (gráfico 2) o aldicarb aparece como responsável pelos óbitos em 10\% dos casos.

Tal quadro de intoxicação por aldicarb não é exclusivo do Estado do Paraná, mas de todo o Brasil, sendo inclusive considerado problema epidemiológico no Rio de Janeiro em conseqüência do expressivo número de intoxicações registradas, semanalmente, no IML-RJ (média de 5 casos /semana). (MORAES, 1999; SAD et al, 2002).

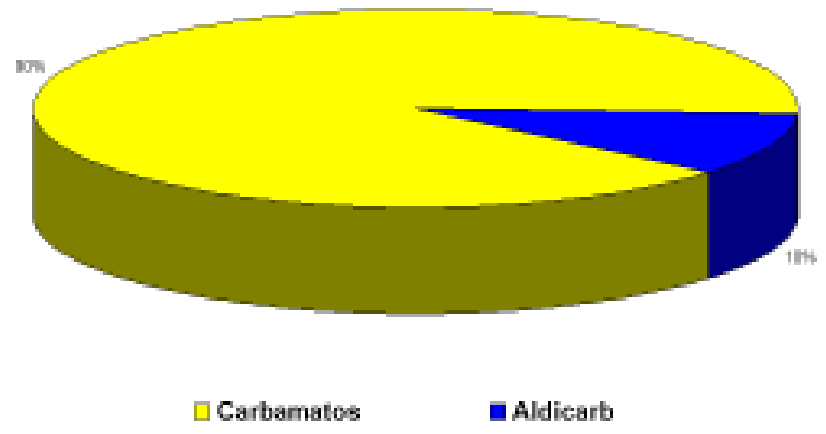

GRÁFICO 2 Ocorrência (\%) de óbitos por Inseticidas Carbamatos, no Estado do Paraná, no período de 10/2000 a 08/2003

FONTE: IML-PR, 2003

É preciso conscientizar a população do Estado do Paraná quanto ao uso responsável de praguicidas e alertá-la sobre os riscos do uso indevido do chumbinho (aldicarb) como raticida, pois o mesmo apresenta uma ação de inibição reversível da acetil colinesterase que determina o acúmulo da acetilcolina, resultando em todas as conseqüências sobre a transmissão nervosa, apresentando uma sintomatologia grave, entre outros efeitos bioquímicos e farmacológicos (LARINE, 1997). Além do que é necessário enfatizar o descaso na fiscalização de tais produtos pelos órgãos competentes, uma vez que as normas legais indicam que a venda de praguicidas e afins, aos usuários, deve ser feita através de receituário próprio, prescrito por profissionais legalmente habilitados, salvo casos excepcionais previstos 
na regulamentação (BRASIL, 1989). Vale ressaltar que um flagrante de venda ilegal resulta na penalização do vendedor e do comprador (BRASIL, 1998).

\section{CONCLUSÃO}

O levantamento realizado no Estado do Paraná, no período de 10/2000 a 08/2003, mostra que o número de intoxicações e óbitos por praguicidas é relevante. Este fato corrobora com a preocupação sobre o uso inadequado destas substâncias pela população. Observase, ainda, a incidência do uso irracional do aldicarb, um derivado carbamato, utilizado, erroneamente, como raticida. Este emprego não é compatível com a indicação legal para este produto, uma vez que está liberado, exclusivamente, como um inseticida.

Esta situação demonstra a necessidade iminente de um trabalho de conscientização da população em relação ao seu uso e além disso evidencia a necessidade de intensificar a fiscalização quanto ao comércio e uso de praguicidas.

\section{REFERÊNCIAS}

PARANÁ. SECRETARIA DE Estado da Agricultura e Abastecimento. Lista de agrotóxicos aptos para uso e comércio no Paraná. Disponível em:http://www.prgov.br/seab/ , acesso 2004

GABRIEL, P.M.K.C.; GABRIEL, M.M.; LOPES, M.; ESCORSIN NETO, J. Proposta para utilização de um método colorimétrico na identificação e quantificação do herbicida paraquat segundo os passos da validação metodológica. I Parte. Visão Acadêmica, v.3, n. 1, p.23, 2002.

ALONZO, H.G.A.; CORRÊA, C. L. Praguicidas. In: OGA,S. Fundamentos de Toxicologia. 2. ed. São Paulo: Atheneu Editora, 2003. p. 437-458.

MORAES, A.C.L. Contribuição para o estudo da intoxicação humana por carbamatos: O problema do chumbinho no Rio de Janeiro. Dissertação de Mestrado. Rio de Janeiro: Fundação Osvaldo Cruz - Escola Nacional de Saúde Pública, 1999.

CANAVIEIRAS, S.A.; LIMA, G.M.B. \& DIAS, E.P.F. Comparação entre os agentes tóxicos envolvidos nas intoxicações por raticidas notificados no Centro de Assistência Toxicológica da Paraíba (CEATOX/PB) e a sintomatologia desenvolvida. Disponível em http://wwwprac.ufpb.br/anais/anais/saúde/raticidas, acesso em 2004.

SAD, C.E.; CARDOSO, K.R.L.; KUBRUSLY, Z.R.S.; OLIVEIRA, S.F.\& ADED, N.L.O. Aspectos médico-legais dos envenenamentos pelo inseticida carbamato aldicarb no rio de janeiro. Anais Brasil Forense. Porto Alegre, 2002. disponível em: http://www.agapel.com.br/forense2002/ver trabalho.asp?tra id=66, acesso em 2003.

LARINE, L. Toxicologia. 3 ed. São Paulo: Manole, 1997.

BRASIL. LEI 7802 de 11 de julho de 1989. Dispõe sobre a pesquisa, a experimentação, a produção, a embalagem e rotulagem, o transporte, o armazenamento, a comercialização, a propaganda comercial, a utilização, a importação, a exportação, o destino final dos resíduos e embalagens, o registro, a classificação, o controle, a inspeção e a fiscalização de agrotóxicos, seus componentes e afins, e de outras providências. Diário Oficial da União, 12 de jul. 1989. Seçãol.

BRASIL. LEI 9605, de 12 de fevereiro 1998. Dispõe sobre as sansões penais e administrativas derivadas de condutas e atividades lesivas ao meio ambiente, e de outras providências. Diário Oficial da União. 13 de fev. 1998. Seção 1 . 